\title{
IRENI Meets Matisse
}

Julia Sedlmair ${ }^{1,2,3}$, and Jennifer Mass ${ }^{4}$, Catherine Schmidt Patterson ${ }^{5}$, Barbara Buckley ${ }^{6}$ and Carol Hirschmugl $1^{1,7}$

1. Synchrotron Radiation Center, 3731 Schneider Dr, Stoughton, WI 53589-3097

2. College of Agricultural Sciences, The Pennsylvania State University, 109 Agricultural Engineering Bldg, University Park, PA 1680

3. US Forest Service, Forest Products Laboratory, One Gifford Pinchot Dr, Madison, WI 53726

${ }^{4}$ Scientific Research and Analysis Laboratory, Winterthur Museum, Winterthur, DE 19735

${ }^{5}$ Collections Research Laboratory, Getty Conservation Institute, Los Angeles, CA 90049-1684

${ }^{6}$ Conservation Department, Barnes Museum, 2025 Benjamin Franklin Parkway, Philadelphia, PA 19130

7. Department of Physics, UW Milwaukee, 1900 E Kenwood Blvd, Milwaukee, WI 53211

Due to its unique Setup IRENI (Infrared Environmental Imaging), located at the Synchrotron Radiation Center (SRC) of the UW Madison, enables diffraction limited full field chemical imaging using synchrotron radiation (SR). The combination of a $3 \times 4$ matrix of beams generated by a bending magnet, which allows for extracting a much larger swath of beam than at common SR-FTIR instruments, with a focal plane array (FPA) makes it possible to record a $34 \mathrm{x} 34 \mu \mathrm{m}^{2}$ area with an effective sample pixel size of about $0.6 \times 0.6 \mu \mathrm{m}^{2}$ within only a few minutes $[1,2]$.

Since its commissioning samples from various fields of research have been investigated with IRENI, e.g. from biology, medicine or astronomy [2]. The application to cultural heritage samples has also been proven recently [3]. Here we would like to present the outcome of studying Matisse's Le Bonheur de vivre (1905-6, The Barnes Foundation) with regard to the cadmium containing yellows.

Nano-crystalline CdS yellow paints used in Impressionist, Post-Impressionist and early modernist work from the 1880s through the 1920s has been observed to undergo poorly understood chemical and physical changes over time, resulting in discoloration accompanying phase transformation. The Matisse sample investigated here has been the subject of research with a number of different microanalysis techniques including XANES, XRF, ATR-FTIR and EM $[4,5]$.

A paint chip from the darkened yellow foliage has been investigated with IRENI producing $\mathrm{CdSO}_{4}, \mathrm{CdCO}_{3}$ and cadmuim oxalate specific images (Fig. 1). The inset in 1a shows a visible light micrograph from a neighboring area. More detailed information is given in the caption. The line scans in Fig. 1d-h) show the transition between $\mathrm{CdSO}_{4}$ and $\mathrm{CdCO}_{3}$. In the comparison between integration images and the correlation with reference spectra it becomes clear that there are significant differences in the distribution of the oxidized $\mathrm{Cd}$ phases. With IRENI important information about the above mentioned processed might become available.

[1] Nasse, M. J. et al., Nat. Methods 8 (2011), p. 413.

[2] Hirschmugl, C. and Gough, K., Appl. Spectrosc. 6 (2012), p. 475.

[3] Unger, M. et al., Appl. Spectrosc. (2012), online. 
[4] Mass, J. L. et al., Appl. Phys. A (2012), online.

[5] Opila, R. L. et al., Microsc. Microanal. 18 (2012), p.896.

[6] Acknowledgments: IRENI was developed under grant MRI-DMR-0619759. The SRC is funded by UW-Madison and UW-Milwaukee.

a)

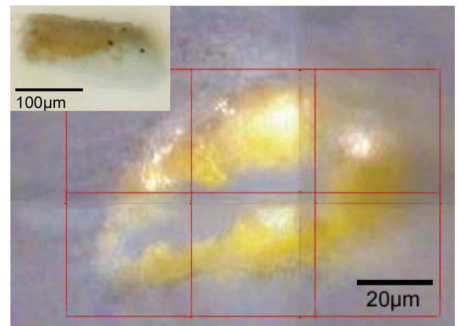

b)
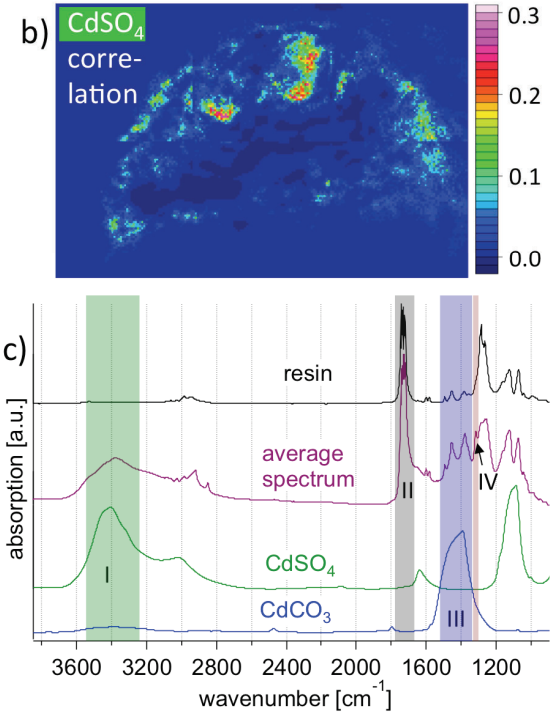

d)

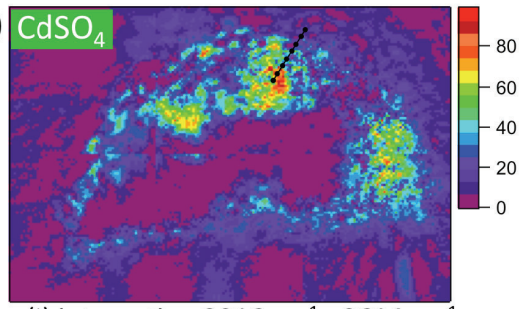

(I) integration $3216 \mathrm{~cm}^{-1}-3614 \mathrm{~cm}^{-1}$

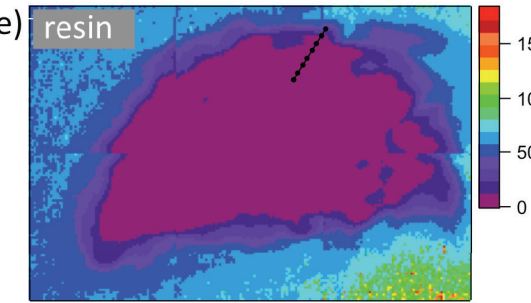

(II) integration $1668 \mathrm{~cm}^{-1}-1786 \mathrm{~cm}^{-1}$

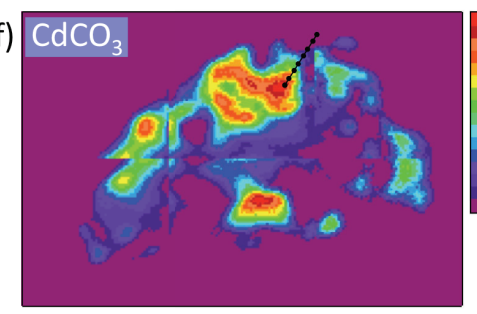

(III) integration $1275 \mathrm{~cm}^{-1}-1534 \mathrm{~cm}^{-1}$

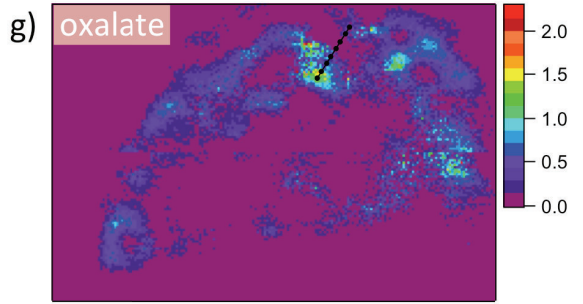

(IV) integration $1304 \mathrm{~cm}^{-1}-1325 \mathrm{~cm}^{-1}$

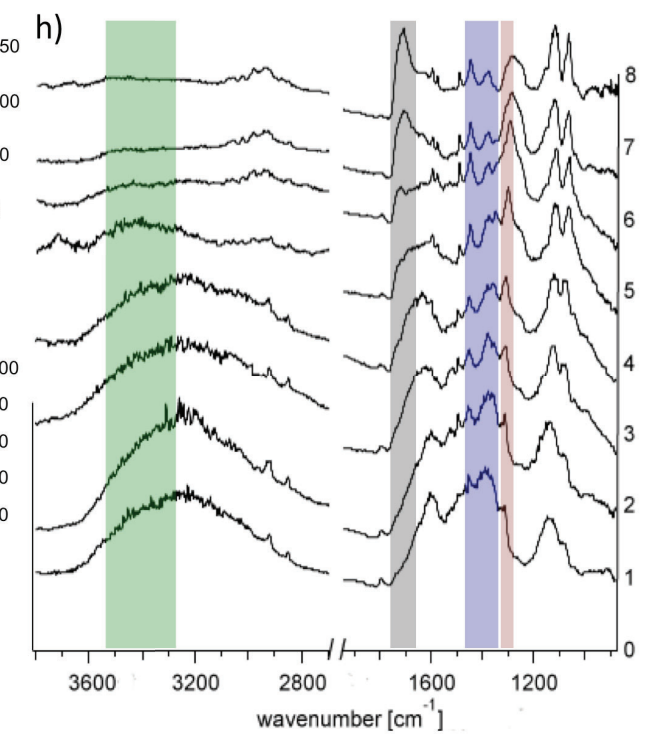

Figure 1. Analysis of the paint chip from the darkened yellow foliage from Matisse's La Bonheur de vivre. a) Micrograph with visible light at $74 \mathrm{x}$ magnification; the inset in the upper right shows a high magnification visible image of the chip, where the alteration layer is clearly delineated as is the layer with the dark precipitate causing the discoloration. b) Result of the FTIR image correlated with the spectrum of $\mathrm{CdSO}_{4}$, shown in c) in green, together with the spectra of the resin (black), the average spectrum of the chip (purple) and $\mathrm{CdCO}_{3}$; the peaks used for the integration images $\mathbf{d - g}$ ) are marked in roman numbers, relevant spectral areas are marked in corresponding colors as follows: characteristic peak for $\mathrm{CdSO}_{4}$ (peak I) in green, for the resin (peak II) for $\mathrm{CdCO}_{3}$ (peak III) in blue and the peak for oxalate (peak IV) in red. d-h) Integration images of the peak areas I - IV as indicated in the plot before, showing the necessity of a differentiated integration in comparison with the correlation image. The hotspots of $\mathrm{CdSO}_{4}$ and $\mathrm{CdCO}_{3}$ are very close together but not overlapping. Oxalate and $\mathrm{CdCO}_{3}$ seem to be co-localized. This can be seen in the plot in $\mathbf{h}$ ) where 8 spectra taken from the line scan (marked in d-g)). The same spectral areas as in c) are marked here, too. For example, an increase of peak III under the peaks of the resin can be observed; the rise of the oxalate peak (red, peak IV) seems to be related. 